Mansoura Englneerlng Jouznal, MEJ, Vol. 14, No: + Jure 1989 E. 7!

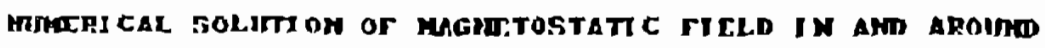

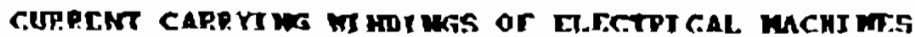

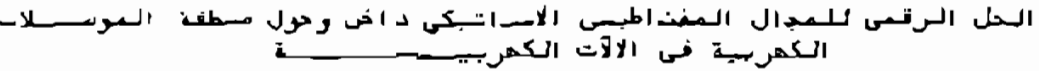

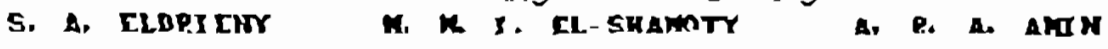

Electrical Engineering Department, Faculty of Englneering, El-Mansoura University, El-Mansoura, E G Y P T

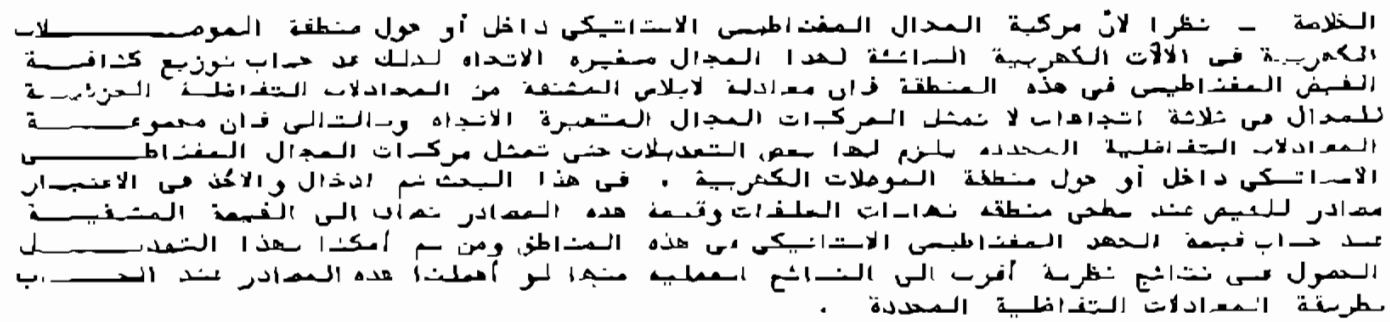

ARGTPACT :

An accurate linomledge uf magnetostatics as well as other field distributicon in electrical machines is of great imporlalle 10 aesign optimization. The search activity in the past two decades has considered the numericaj analysis ancl calculation nf magnetostotic fiplu in electrical machinery through the solutian of Maxwell's equations. while taring full account of magnetic saturation. This solution of field problem is limjted to simple geometric shapes of the region of interest. Concepts of both scalar and vector magnetic potential have been used for computing the magretustatic fields. Numerical approaches involving finite-element method, finite-difference method and integral equation technique may he used to evaluate sulh fields.

In ejectricdl machines, the flux distributinn reguirod is that in an. around current carrying windings. Cansequently the partial differential equation such as Laplace's equation for the behaviour of magnetostatic fields is not valid within current carrying conductors. Within the conductor there is no defintion in the finite-difference mesh. It is however possible to Jerive another potential function inside the current-carrying regions which do not satisfy Laplace's equation 
B. 76 S.A. El-Drleng, M.M.I. El-Shamoty, and A.R.A. Amin

throemout the conductor, but enable the field problen to be colved and allaw calculation of magnetic field strength and flux denslty. Theeo equations affect a solution of Polgeion's equatjon which dogs nold inside a current-carrying reglon but only for vector magnetic potentials.

This paper presents the development of finite-difference method for solving throe-dimentional scalar magnetostatic potential in and around current-carrying windings in electrical machines. Consequently, an approprlate field sources and the armature current distribution in slotted sections and ovorhang regions are easy derived.

\section{I HTRODUCTI OH :}

The flures in the end regions of electrical machine are generated by windings mose end-connections are of comples: shape, and these generate a three dimensional flux pattorn whose computation is of increasing importance in linear machines and similar cases. The winding inrces can satisfactory be predicted by numerical integration over the current elements, Dut this is not well suiigd to the prohlem of field prediction in and around the surrounding materials. Differential methods are ther: more convenient, preferably in terms of a scalar function since trip magnetic vector potential has three components. In proctic, ti.= complexity of the end winding and the need to specify three componenls of the current density vector malies it difficusl to provide a sultably simplified model to describe the end-wnding: and hence the jcalor potentid field sources which wh therlyed fram it.

For nuany murprises, it is corivenient to compute the fields in terms of travelling waves. The comfutation of the sources of each wave component, in numerical terms, demands firstly; a simple description of the current diatrlbution in the region af current carring winding, such as slotted sections and the over hang region, secondly; an insight into the various ways which it $c$ an be transformed.

The paper presents a development of finite difference method for solving three dimensional scalar magnetostatic potential in and arround current carrying windings. This development examines the general problems of transiating complex current distribution into equivelent nodal sources for a numerical scalar potential computation by finite difference method. The method is applied to linear synchronous machine and regjon and illustrated by field solution.

\section{TIE BASTC AMALOGUE OF ST HGLE MODE :}

The FDM places the nodes at the corner of cubes, the cube has $1 \mathrm{~cm}$ length. Each of the six elements connected to a node is taken to have 
unl permeance unless an iran boundary 15 less than 1 cm distance when the reluctance is proportionaly small. Mus, in fig.1. the nodo potential is given by:

$$
P_{1}+P_{2}+P_{3}+P_{4}+P_{5}+P_{6}-o p_{0}=0
$$

Where p 15 the magnetic scalar potentlal difference betmeen different points and denotes the magnetomotive force which excits betmeen these points. In the case of a half pole pltch region in an electrical machlne, the three dimensiomal mesh is 11 kely to have several thousands of uranches, therefore it is solved by rapresenting it in a camputer and applying a technique known as successive over relaxation (50p). Relaxation af a network comsists of treating all nodps in soquence of une node at a time. If the left hand side of the above equation is evaluated for an arbitrary choise of mode potentials, a quantity not oqual to zero will most likely. result. This is cajled residual and is proprtional to the total +1 ü converting on the central node. The residual at all nodes should fur successive iteration cone calculation per node for all nodesl be very small compared with fluy passing through any one element (they stiald ldeally be zeral. If the potential pa is adjusted after each iteration the residual for the node can be reduced to tero. Ey treating nodes one a time, many times over,the successive adjustments cause the residuals to gradualiy diffuse around the mesh to be absarbed by the boundaries of a constant potential. This is callpn suctessive relaxtion. Nou the residual $R$ is given by :

$$
P=p_{1}+p_{2}+p_{3}+p_{4}+p_{5}+p_{6}-p_{D}
$$

Adding a quantity of R/b may reduce the residual to zero. Adding a quantity aR/t, if $\alpha$ is greater than one, causes a greater change. Where a affects the convergence of the 5ulution. Higher values of a improve the rate of convergence, but it too large a value is used instability and oscillation may resule, theroby preventing convergence may be obtajned [ 5 ].

$$
4 \text { " }
$$

\section{CURPEET DI STP.1 BUTT OH :}

A useful method is described by Carpenter 441 where the electric circuits (the current carrying region) and the magnetic circuits (the comblete filed including the space inside the conductorl are initially torn apart. This is illustrated for a rectangular conductor (Fig 2a) as follows. 
E. 78 S.A' El-Drleng, M.M.'I. El-Shamoty, and A.R.A.' Amin

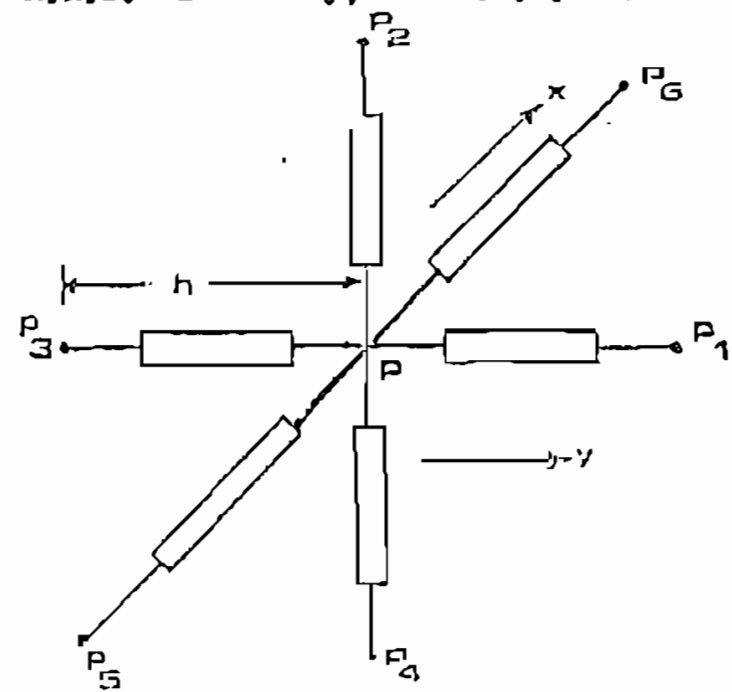

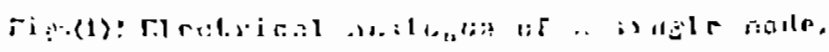
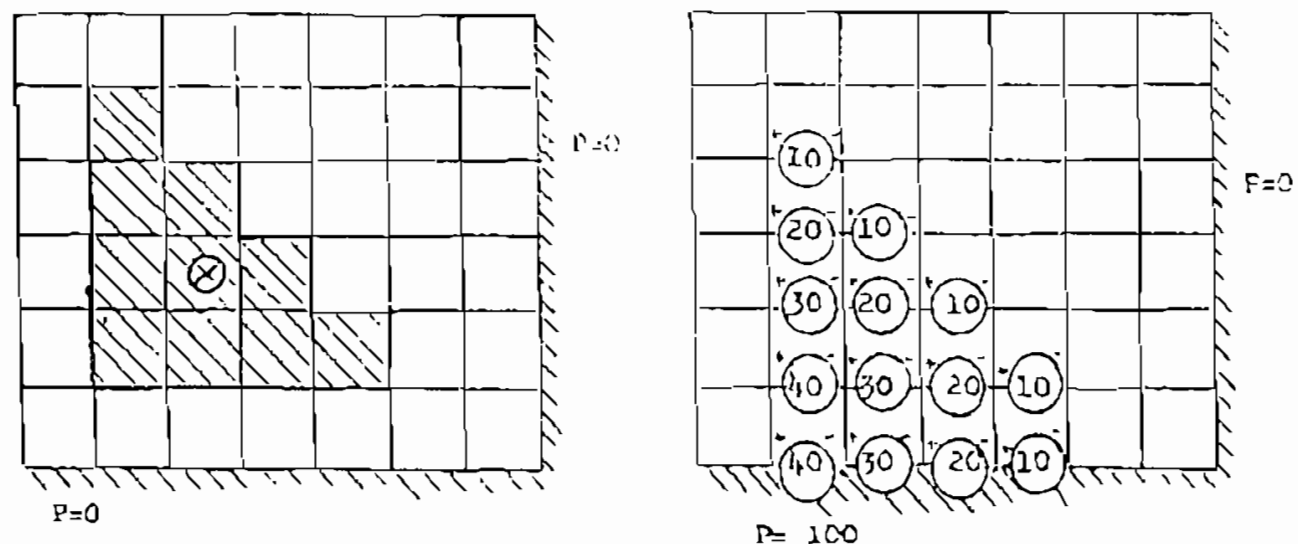

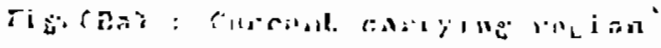

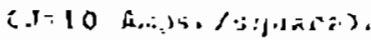

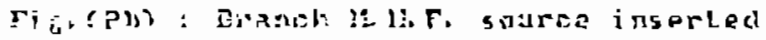
arker learing lbe rogatriar .1:1. ni l.he lisash. 
(a) The conductur is torn from the mesh circut analogue in the downward direction.

(D) Aranch sources of potential are inserted, which have been brakon In the tearing procoss, equal to the ampere conductor which have passed through the branch. The path of withdraw of any cunductor is arbitrary, see Fig.2b.

(c) The branch sources are converted to their Norton equivalents ifig $3 a$ and $3 b l$. The flux source values are simply added ta tho roridual calculated at the noge during relaxation. The conductor has collapsed to from a current sheet on the iron surface and the branch sources have been retained to dafine the fixed potentials.

(d) The relaxation nrocess is then exiecuted resulting in a non-zero divergence field solution. The solution is valir overywhere except within the arigind canductar sectionl.

(e) The introduction of $f 1 u x$ sourcec abviausly created a fiejd of non-zero divergence. The potential function now defined within the conductor ropresents a fleld which is grossjy distorted.

The figld outside the region converted by flux sources 1 s currectly detined by the normal magnetostatic potentlal function but within the conductor, corrective fields of opposite divergence must be added to thase calculated frap the function. This complementary fipld is defined by branch sources as shown in Fig 4. This method was used simply to represent the field and armaturewindings. In the case of the latter the winding $1 \mathrm{~s} 5 \mathrm{implified}$ to a thick current sheet with components in axial (x) and transverse (y) airections. The currents are assumed to be uniformly distributed in the (z) direction for dopth of the winding- It is not possiole to define separate current distributions for the top and botton layers of the winding without both gestroying the symmetry and the need for a mesh of twice the size. The winding is withdraw from the mosh oy collapsing the end turns (averhangl snto the sides of the centre $1 \mathrm{imb}$ (FIg 5a,5t) thus forming curront. Sheets along the slat ends rather I ike the end rings of a squirrel cage rotor. Flux sources appear an the upper and lower surface of the uinding. The complementary fjeld is applied between the two layers of flux sources and has a comporient in tho 2 direction only. The magnitudes of flux source are derlved as fol 1 ows:

\section{1. Nagneto Wolive Furce in slated Seclions:}

The arouture rinding 35 represented by a thick current sheet, assuming that current is uniformly distributed in the (x) direction. If tlis winding has short chorded calls of pitch $C_{p}$, the displacement between the two poaks of current loading in the top Jayer and bottom 
E. 80 S.L. E1-Drieng. M.M.I. B1-Shemoty, and A.R.'A.' Amin
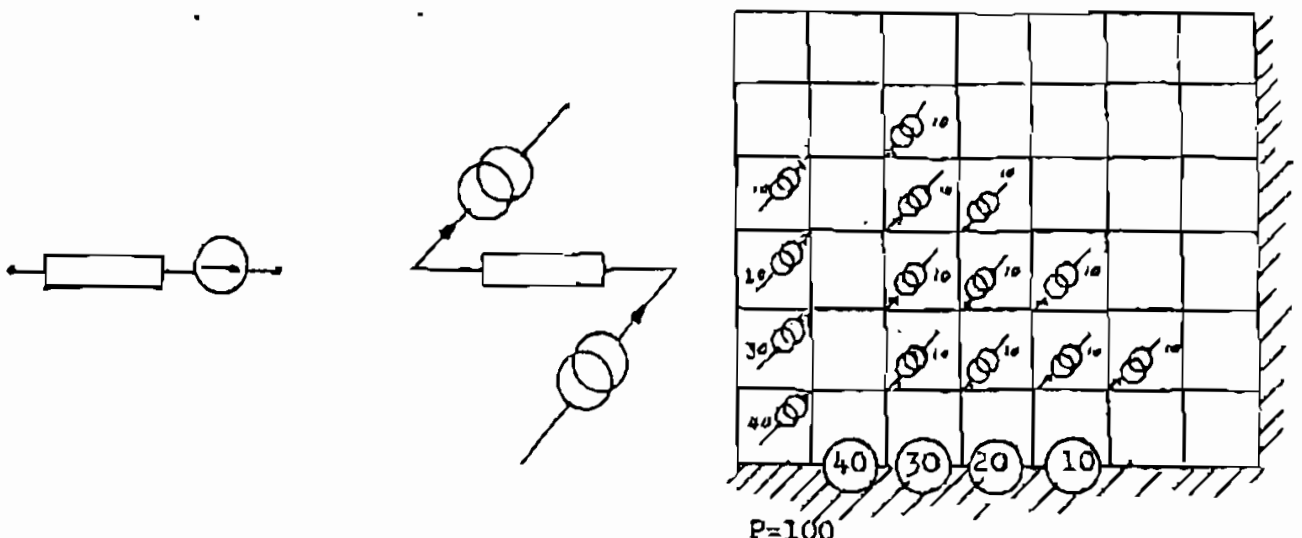

ric.(3a) : Horlon eguivalenl. of braigrh SDirtip.

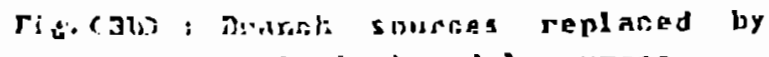
eruivalenl nutel soures.

rigi(4) : Tlle coinglewenlary rield raving. - olulusila divereunce.

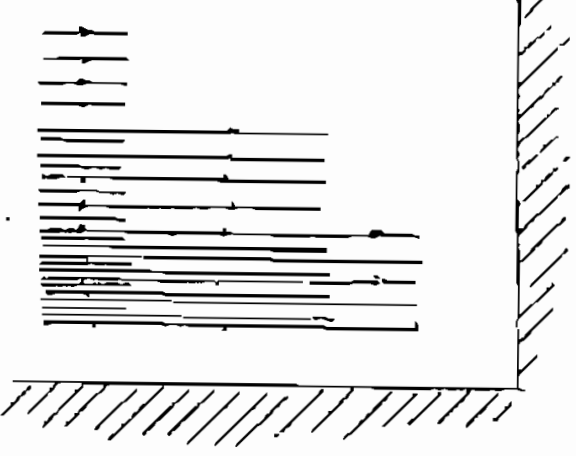


Nansoura Englneertng Journal, KEJ, Vol, 14, No: $;$, June 1989 B. 81

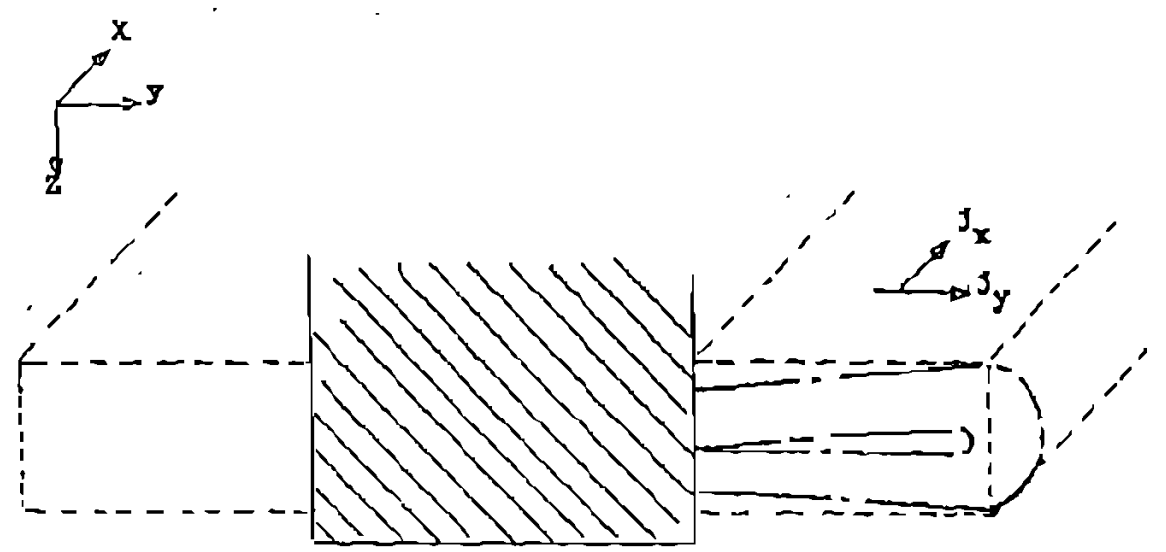

rle. (sa) : Arualure winding as a Lhisl: curront sheel.

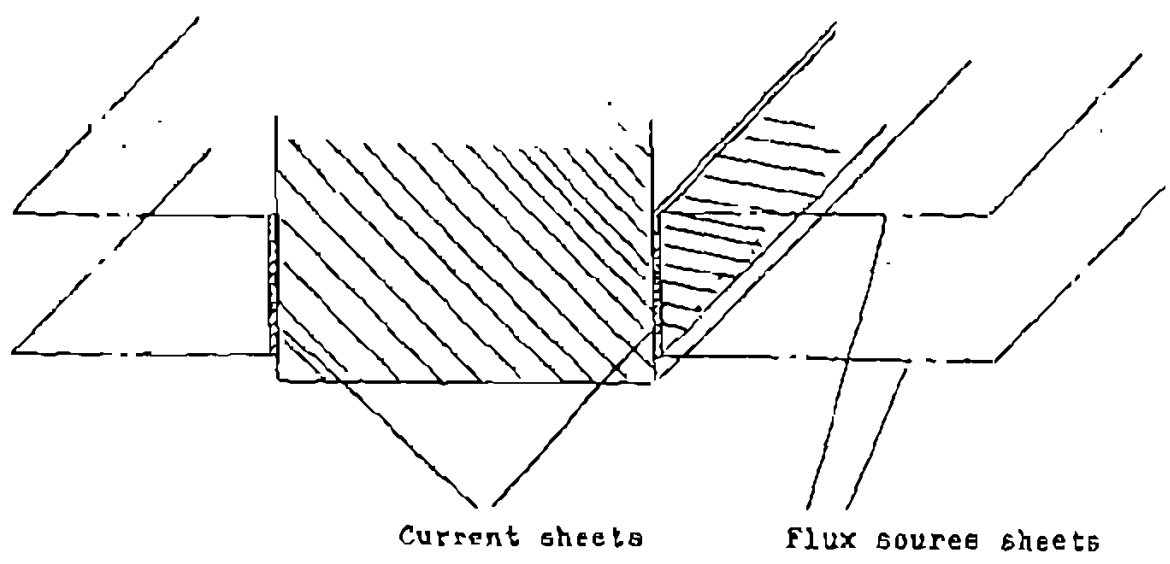

rig. (5b) : End Lurns callapised La form rurcerll seels and nodals rlux suurces inserted, 


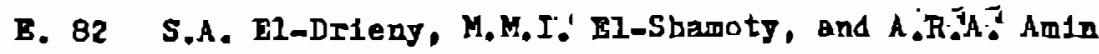

layer windings will be

$$
\text { o }=n\left(1-\left(c_{p} / p\right)\right)
$$

Hore $C_{b}$ is coil pitch, p is pale pltch.

If the peak current 1 bading is $\hat{J}_{D}$. then the current distribution in the slated region 15 made up of two compenents:

(i) due Lo upper 10 conductore;

$$
J_{e I}(x)=\frac{\hat{J}_{0}}{2} \cdot \cos \left(\frac{n x}{p}-\frac{\delta}{Z}\right)
$$

(ii) due Lo lower siol eanduchars,

$$
J_{s 2}(x)=\frac{\hat{J}_{0}}{2} \cdot \cos \left(\frac{n x}{p}+\frac{\delta}{2}\right)
$$

The total current loading is the sum of the previous two components and Is giver by:

$$
J_{s}(x)=\hat{J}_{0} \cdot \cos \frac{\theta}{2} \cdot \cos \frac{n x}{p}
$$

Hence, the magneto motive force, ......, of the slotted section 15 given by:

$$
\begin{aligned}
F_{s}(x) & =\int J_{s}(x) \cdot d x \\
F_{s}(x) & =\hat{J}_{0} \cdot \cos \frac{\delta}{2} f \cos \frac{\pi x}{p} d x \\
& =\frac{\hat{J}_{0} P}{\eta} \cos \frac{\delta}{2} \sin \frac{\pi x}{p}
\end{aligned}
$$

Assureing,

$$
\hat{J}_{D}-p / n=100 \text { units }
$$

For the direct ax1s armature field with its peak m.a.t. caincides with the pole centre $(x=1)$ and varying sinusoidally to zero m.n.t. at the half pole pitch mesh $(x=p / 2+1)$. The FDM solution represented aver a quarter of a full m.A.f. wave. For the direct axis, the m.A.f. equation Is ;

$$
F_{5}(x)=100 \cdot \cos \frac{\delta}{2} \cdot \sin \frac{\pi}{p}-\left(\left(\frac{p}{2}+1\right)-x\right)
$$


For quadrature axis field, with xaro m.t.t. corresponding to the pale centre $i x=1)$ and varying sinusoidally to a pak a.e.t. at the halt pole pltch $(x=p / 2+1)$. the m.n.t. Uquation 19 .

$$
F_{s}(x)=100-\operatorname{cog} \frac{6}{2} \cdot 5 \ln \frac{\pi}{p}(x-1)
$$

\section{A. R. Macmelo welve rorce in orerhanc section:}

In the overnang the top laver conductors will be angled formards (tre $x$ direction) and the botton layer conductor wlll bo angled backwards with respect to the axis (x) of the stator. At a point $p(x, y)$ in the overhang (soe flg ba) the top layer produces the following currenks.

$$
\begin{aligned}
& J_{y}=J_{s 1}(x-a) \\
& J_{x}=J_{\leq 1}(x-a) \cot \theta
\end{aligned}
$$

and the bottom layer will contribute;

$$
\begin{aligned}
& J_{y}=J_{52}(x+a) \\
& J_{x}=J_{52}(x+a) \cot \theta
\end{aligned}
$$

Where, $\cot \theta=c_{p} / 2 w_{0}$ and $w_{j}$ is the overnang length.

$$
a=y \cot \theta=y \cdot C_{p} / 2 \omega_{a}
$$

The current distributions are therefore:

$$
\begin{aligned}
J_{y}(x, y) & =\frac{\hat{J}_{g}}{2} \cos \left(\frac{\pi x}{D}-\frac{1}{2}-\frac{\pi y C_{p}}{2 \pi a_{a}}\right) \\
& +\frac{\hat{J}_{g}}{2} \cos \left(\frac{\pi x}{p}+\frac{\delta}{2}+\frac{\pi y C_{p}}{2 \pi a_{a}}\right.
\end{aligned}
$$


B. 84 S.A. El-Drleny, M.M.I. El-Shemoty, and A.R.A. Aa1n

$$
\begin{aligned}
& d_{x}(x, y)=\frac{\hat{J}_{q} c_{p}}{4 \omega_{a}} \cos 1 \frac{\pi x}{p}-\frac{d}{2}-\frac{n y C_{p}}{2 m_{d} p}, \\
& -\frac{\hat{J}_{0} C_{p}}{4_{n}} \cos \left(\frac{\pi x}{p}+\frac{\delta}{2}+\frac{n y C_{\beta}}{2 \omega_{a} p}\right) \\
& J_{Y}(x, y)=\hat{j}_{D^{-}} \cos \left(\frac{\delta}{2}+\frac{\pi \gamma C_{p}}{2 \omega_{B} p} \cos \frac{\pi x}{p}\right. \\
& J_{x}(x, y)=\frac{\hat{J}_{o} C_{p}}{2 w_{p}} \sin \left(\frac{\delta}{T}+\frac{\pi y C_{p}}{2 \omega_{a} p} \sin \frac{n x}{p}\right.
\end{aligned}
$$

These expressions may be checked by calculating div $J$ and equating it to zera.

$$
\begin{aligned}
& \operatorname{div} J=\frac{\partial J_{x}(x, y)}{\partial x}+\frac{d J_{y}(x, y)}{\partial y} \\
& \frac{\partial J_{x}(x, y)}{\partial x}=\frac{\hat{j}_{n} C_{p}}{z_{a}} \cdot \frac{n}{\tilde{p}} \cdot \sin \left(\frac{\delta}{z}+\frac{n y C_{p}}{2 \omega_{d} p} \cdot \cos (n x / p)\right. \\
& \frac{\partial J_{y}(x, y)}{x}=-\frac{\hat{j}_{q} c_{p}}{2 \omega_{a}} \cdot \frac{\pi}{\bar{p}} \cdot \sin \left(\frac{\delta}{z}+\frac{\pi y c_{p}}{2 \omega_{a} p} \cdot \cos (\pi x / p)\right. \\
& \text { Hence, } \quad \frac{\partial J_{x}(x, y)}{\partial x}+\frac{\partial J_{y}(x, y)}{\partial y}=0
\end{aligned}
$$

If, as shown In Fig-bb. the averhang $1 \mathrm{~s}$ collapsed to form a thin sheet on the sides of the core, the branch potentlal source which must appear along AB, wust be equal to the ampere turng which nave cut the line AB.

$$
\begin{aligned}
& F_{0}(x, y)=\int_{y}^{n_{a}} J_{x}(x, y) . d y=\frac{\hat{J}_{o} C_{p}}{2 \sigma_{a}} \sin \frac{\pi x}{p} \int_{y}^{n_{a}} \sin \left(\frac{\delta}{2}+\frac{\pi y C_{p}}{2 n_{a} p}\right) . d y \\
& =\frac{\hat{J}_{q} c_{p}}{\pi} \sin \frac{\pi x}{p}\left[\cos \left(\frac{\delta}{2}+\frac{n y c p}{2 \sigma_{a} p}\right)-\cos \left(\frac{\delta}{2}+\frac{c_{p}}{2 p}\right)\right]
\end{aligned}
$$

since $\delta x n\left(1-c_{p} / p\right)$ the last tern 15 zero, hence the m.m.f. in the 
Mangoura Englneering Journal, MEJ, Vol, 14, No: 1, June $1989 \quad$ E, 85

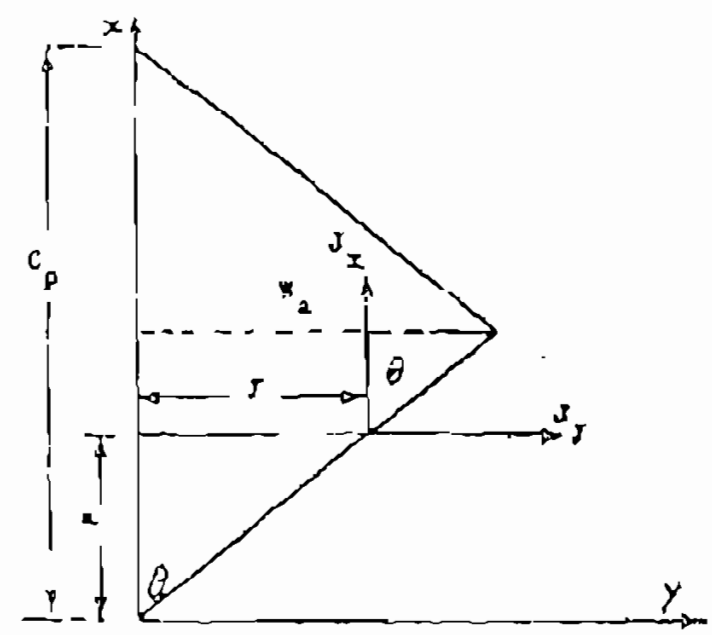

(a)

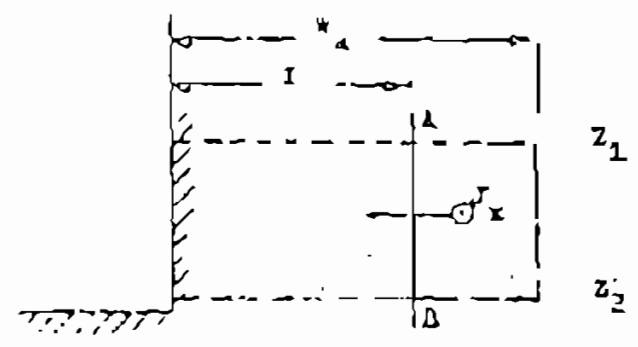

(b)

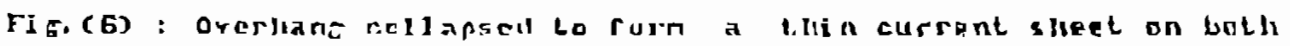
sides of lhe corp and nodals lius sudrcps appeared on lna p1 anes $z_{1}$ and $z_{2}$. 
owerhang ext1on II given by

$$
F_{0}(x, y)=\frac{\hat{J} p}{n} \cos \left(\frac{d}{z}+\frac{\pi y c_{p}}{2 \pi a^{p}}\right) \sin \frac{\pi x}{p}
$$

If substituted by equation (7) Into Eq. (18), hence I

$$
F_{0}(x, y)=\frac{F_{s}(x)}{\cos \frac{\delta}{2}} \cos \left(\frac{\delta}{2}+\frac{\pi y C_{p}}{2 \sigma_{2}{ }^{g}}\right), 0<y<\omega a
$$

If $y=0$ then $F_{g}(x, y)=F_{s}(x)$

If $y$ a then $F_{0}(x, y)=0$

The nodal flux sources appearing on the surface planes are:

$$
\begin{aligned}
& F_{0}\left(x_{0} y\right) /\left(z_{2}-z_{1}\right) \text { for plane } z_{2} \\
& F_{0}\left(x_{1} y\right) /\left(z_{2}-z_{1}\right) \text { for plane } z_{1}
\end{aligned}
$$

For the part of the armature winding between the core and the first bend, flux sources using the potential $F_{5}(x)$ are used.

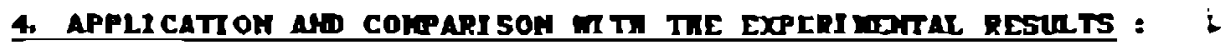

The method is elaborated in this paper and lliustratad by translating conplex current distribution of the overthang sections inta equivalent nodel flux sources appearing on the upper and lower surface of the winding in the overthang reglon. The complenentary fleld is applied between the two layer of $f 1 u x$ sources and has a component only in the direction perpendlcular to the planp containing the over hang winding 12-direction). Th1s method 1s applied easy to IInear synchro naus nachine over-hang and 11 lustrated by fleld soluticrs. The stator sreature windings are composed of a number of cantinuously distributed and unifornly spread coils which span $2 / 3$ of the pole pitch.

The computation of the lield due to A.C. windings was carried out assuning sinusaidal distribution of both ermature current and M.M.F.. In reletion to the track poles the windings M.M.F. was regarded as comprising a direct-axis and quadrature axis sinusoidally distributed component. 
(a) The armalure direct-axas rield:

The direct-axls field has the same symnetry as the nagnetizing field and few changes to the computations werg required. The side limbs are set at zero potential. wile along the centre limb the potentlal is set to vary sinusoldally. The peak of the M.M.F. wave (an arbitrary rofrence of 100 units) coincides with the polacentre and the mesh covers one quarter of a length. The equation of M.m.F. oistributsan at the armature surface Is:

$$
100 \cos \left(\frac{n}{p p}(x-1)\right)
$$

and $x$ varies from $x=1$ at the pole centre to $x=p p / 2+1$

(b) The armalure quadralure axd riejd:

The quadrature axis field has a different symmetry aince the track-pole axis coincides with the zerp point of the armature M.M.F. wave. This means that the pole and $Y-Z$ plane passing through the pjle centre must also be at zero potential. The field beconeb almost entirely arial since the pole and unth side limbs are at zero potential. The distribution sf M.M.F. at the armature surface is given by:

$$
100 \sin \left(\frac{\pi}{P P}(x-1)\right)
$$

and $x$ varies from $x=1$ at the pole centre to pp/2+1.

The mesh covers orie quarter of wave length. The compensation of the overhang turns is treated separately as proviously explained. The larout of 3-dimensions for hal polepitch, Fig.7, representes the coil and overhang dimensions. The flow-chart, Fig.8, represents the butined $f l u x$ sources due to A.C. windings in the overthang and slotted sections according to the previously analysjs.

Laboratory measurements wich are carried on the experimental model, [6] show for gond approximation, a resonable agreements witn the devalped technique represented in this paper. The following table shows the comparison between the experimental measurements, computed results, and the computed developenent FDH of armaturo flux/pole for 100 AT

\begin{tabular}{|c|c|c|}
\hline $\begin{array}{l}\text { Exper } 1 \text { mental } \\
\text { Heasurenents }\end{array}$ & $\begin{array}{l}\text { Computed Results with } \\
\text { Consideting Fl(1x Sources } \\
\text { (Developed Technique) }\end{array}$ & $\begin{array}{c}\text { Computed Results } \\
\text { Wi thaut Consider ing } \\
\text { Flux Sources }\end{array}$ \\
\hline $3.1 \times 10^{-2}$ & $3.2 \times 10^{-2}$ arb. & $3.4 \times 10^{-2}=0$. \\
\hline
\end{tabular}
excitation.

Comparison between the experimental neasurements and the two computed results of armature flux per pole for 100 AT, $10 \mathrm{~mm}$ air gap, and pole depth $20 \mathrm{~mm}$ 
B. 88 S.A. EI-Drleny, M.M.I. El-Shamoty, and A.R.A. Amin

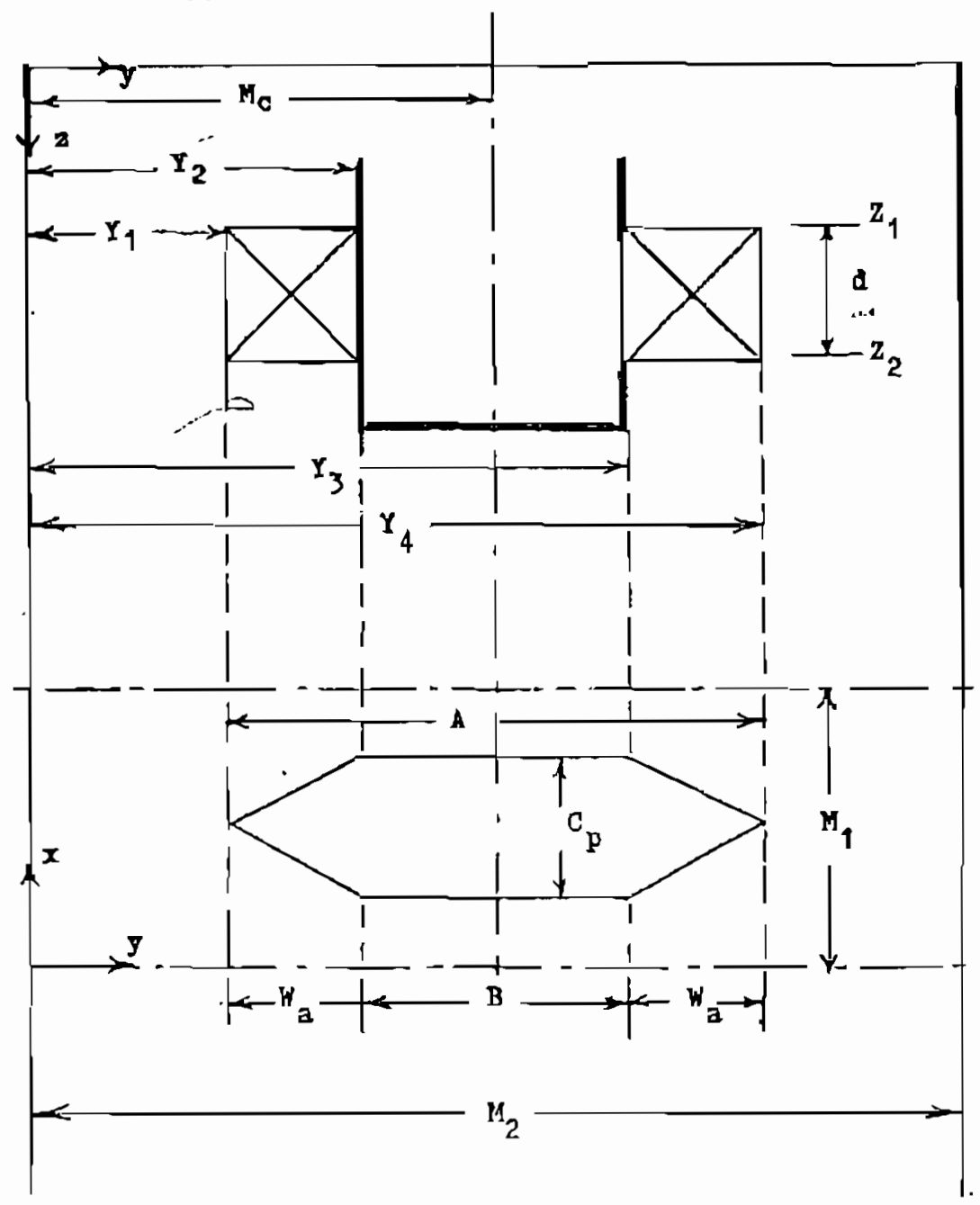

riz.(3) : Laynul or three dimension for liale pole-gileh showing the enil and over-hane dinensions. 


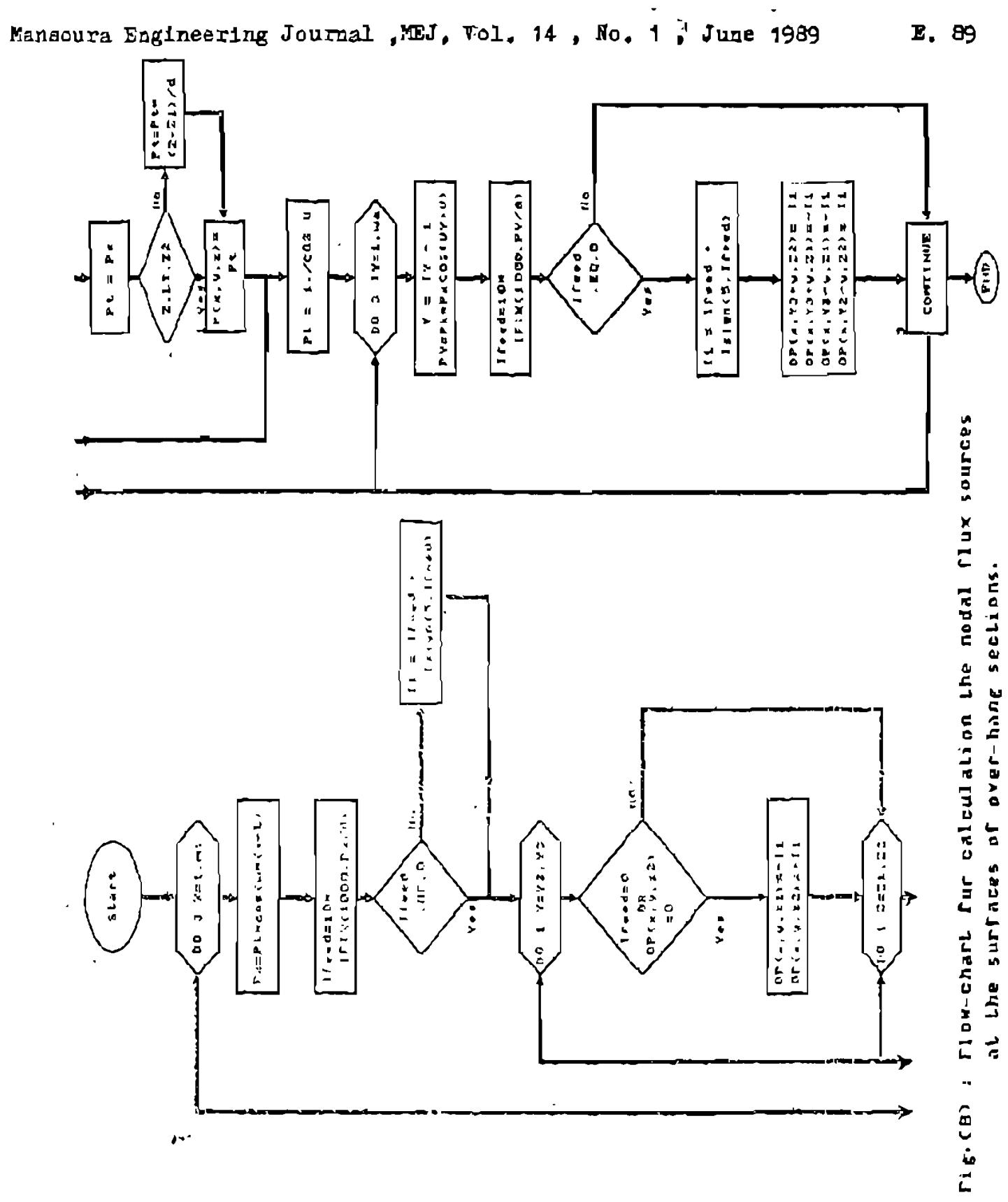




\section{COMCLUS1 OH :}

The flnite difference method for solving three dimentional scalar aqnetostatic potential in and around current-carrying windings in electrical achines has been developed and presented in this paper.

The armature current distribution and the magnetonotive force M.M.F. in both the over-hang and slotted sections are derived. The approach adopted In this paper has been witten in Fortran four computer program and nodal flux sources appearing on the surface planes of the over-hang section are added to the residual during calculation of the nodes potential of these planes. The approach has been applied to a network model represonts a static linear synchronious motor excited with one hundred of M.M.F. alternating current. The armature flux per pole has been measured and it has a resonable agreement with the developement of finte difference method FDM.

\section{RETERITKES :}

1- Binns,K.J. and Lawrensnn, P.J., Analysis and computation of electric and magnetic field problems", Pergamon Press Ltd., 2nd edition, 1973 .

2- Sylvester, P.,"Modern electromagnetic fields" Prentice Hall, 1968.

3- Vitkovitch, D., "Field analysis : experimental and computional methods" , Van Nostrand, 1966.

4- Carpenter, C.J., "Numerical solution of magnetic fiejds in the vicinity of current-carrying conductors", Proc. I.E.E., Vol. 114, No. 11, Nov. 1967.

5- Carpenter, C.J., "Finite-element network models and their application to eddy current problems", Proc. I.E.E., 1975. Vol. 122, pp 455-462.

6- El-Drieny, 5.A.: - Optimization of track-pole geometry for E-core homopolar linear synchronous motor", Mansoura Engineering Journal * Vol. 12 , No. 2., Dec. 1987. 


\section{L15T or 5rubals:}

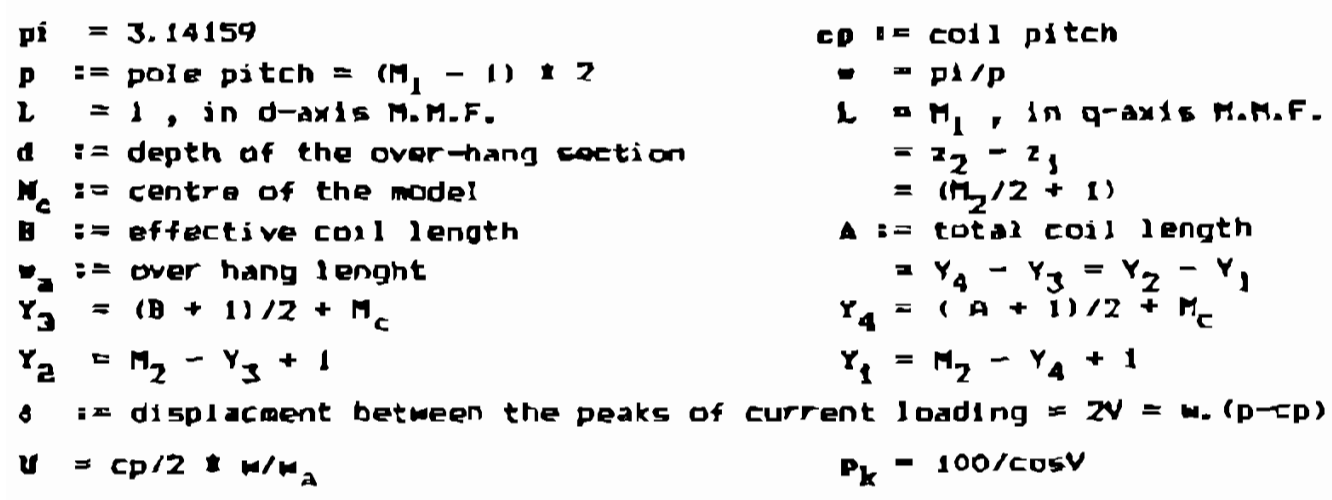

